\title{
Efeitos do diclosulam na soja cultivada em solos de diferentes classes texturais ${ }^{1}$
}

\section{Diclosulam effects on soybean grown in soils of different textural classes}

\author{
Tiago Gazola²; Márcio Furriela Dias³; Diego Belapart ${ }^{4}$; Edicarlos Batista Castro ${ }^{5}$; Leandro \\ Bianchi $^{6}$
}

\begin{abstract}
Resumo - O uso de herbicidas em pré-emergência da cultura da soja é uma ótima ferramenta para o manejo de plantas daninhas. Porém é importante conhecer os efeitos de herbicidas, a fim de evitar decréscimo na produtividade. Assim, o objetivo deste experimento foi avaliar a sensibilidade de três cultivares de soja submetidas à aplicação do herbicida diclosulam em pré-emergência em solos de textura argilosa e média. Os experimentos foram conduzidos em casa de vegetação no delineamento de blocos inteiramente casualizados com quatro repetições, em esquema fatorial 6x2, onde o fator A correspondeu a diferentes épocas de pulverização do herbicida diclosulam, todas em pré-emergência, sendo: testemunha sem aplicação, 28, 21, 14, 7 e 0 dias antes da semeadura (DAS) da soja e o fator B correspondeu as texturas dos solos. As cultivares utilizadas foram a $\mathrm{M}$ 6410 IPRO, NS 6906 IPRO e NS 7000 IPRO. A semeadura ocorreu ao final das pulverizações dos tratamentos no dia 0 DAS. Avaliou-se o índice de velocidade de emergência (IVE), porcentagem de fitotoxicidade, altura de plantas, massa seca da parte aérea e massa seca do sistema radicular. De acordo com as metodologias empregadas neste experimento, o herbicida diclosulam aplicado em pré-emergência nos solos de textura argilosa e média é seguro para as cultivares de soja analisadas, pois não provocou efeitos negativos no desenvolvimento das plantas.
\end{abstract}

Palavras-chaves: Glycine max; inibidores da ALS; seletividade; sensibilidade

\begin{abstract}
The use of herbicides in pre-emergence of the soybean crop is a great tool for weed management. However, it is important to know the effects of herbicides in order to avoid a decrease in productivity. The objective of this study was to evaluate the sensitivity of three soybean cultivars submitted to pre-emergence application of diclosulam in clayey soils and average. The experiments were conducted in a greenhouse in randomized complete block design with four replications in a $6 \times 2$ factorial, where factor A corresponded to the treatments and the B factor was the soil textures. The treatments were different herbicide spraying times diclosulam, all pre emergency, being: without application, 28, 21, 14, 7 and 0 days before sowing (DAS) soybeans. The cultivars M IPRO 6410 NS 6906 NS 7000 and IPRO IPRO. Sowing took place at the end of the spray treatments at day 0 DAS. We evaluated the emergence speed index (EVI), percentage of phytotoxicity, plant

\footnotetext{
${ }^{1}$ Recebido para publicação em 01/08/2016 e aceito em 13/10/2016.

2 Mestrando em Agronomia, Dep. de Proteção Vegetal da Faculdade de Ciências Agronômicas - FCA/UNESP, Botucatu, São Paulo, Brasil. E-mail: 〈tiago-gazola@ hotmail.com〉.

3 Engenheiro Agrônomo, Universidade de Marília - UNIMAR, Marília, São Paulo, Brasil. E-mail: <marciofdiass@outlook.com>.

${ }^{4}$ Doutorando em Agronomia, Dep. de Produção e Melhoramento Vegetal da Faculdade de Ciências Agronômicas FCA/UNESP, Botucatu, São Paulo, Brasil. E-mail:<diegobelapartt_@hotmail.com>.

${ }^{5}$ Doutorando em Agronomia, Dep. de Proteção Vegetal da Faculdade de Ciências Agronômicas - FCA/UNESP, Botucatu, São Paulo, Brasil. E-mail:<castroeb@hotmail.com>.

${ }^{6}$ Mestrando em Agronomia, Dep. de Produção e Melhoramento Vegetal da Faculdade de Ciências Agronômicas FCA/UNESP, Botucatu, São Paulo, Brasil. E-mail:<Leandro_bianchii@ hotmail.com>.
} 
height, dry weight of shoot and dry root weight. According to the methodologies used in this experiment, the herbicide diclosulam applied in pre emergence in clayey soils and average is safe for soybean cultivars analyzed, it did not cause negative effects on plant development.

Keywords: Glycine max; ALS inhibitors; selectivity; sensibility

\section{Introdução}

A soja é a oleaginosa mais importante no mundo e o Brasil destaca-se neste cenário com uma produção total de 95 milhões de toneladas na safra 2015/16, colocando-o no posto de segundo maior produtor mundial, atrás apenas dos EUA (CONAB, 2016). Entretanto, a produtividade das culturas é afetada por fatores bióticos e abióticos, dentre eles a competição com plantas daninhas. Desta forma, surge a necessidade de manejar estas plantas infestantes e dentre as ferramentas existentes a principal é o controle químico.

No entanto, é necessário conhecer adequadamente um herbicida para que o mesmo possa ser utilizado com eficácia e seletividade para as culturas de interesse econômico. Dentre os diversos herbicidas com registro no Ministério da Agricultura Pecuária e Abastecimento (MAPA) para uso na soja, o diclosulam é bastante difundido entre os agricultores por se tratar de um produto seletivo para a cultura e quando aplicado em préemergência das plantas daninhas apresenta ótimos resultados de controle.

O diclosulam é um herbicida de aplicação em pré-emergência das infestantes e pertence ao grupo químico das triazolopirimidinas, sua ação é na inibição da enzima acetolactatosintase (ALS), a qual é essencial para a síntese de aminoácidos valina, leucina e isoleucina (Rodrigues e Almeida, 2011). A redução nos níveis de aminoácidos acarreta em distúrbios na produção de proteínas, interferindo no crescimento celular, provocando necrose no meristema apical e paralisação do crescimento das plantas (Fleck e Vidal, 1994).

A degradação de moléculas de herbicidas no solo e sua capacidade de sorção influenciam diretamente a persistência destes compostos no ambiente (Oliveira e Briguenti,
2011). Desta forma, o comportamento do diclosulam é fortemente influenciado pelos teores de umidade, argila e matéria orgânica do solo (Rodrigues e Almeida, 2011). Assim, o diclosulam possui efeito residual, o que contribui para evitar fluxos de emergência de plantas daninhas no estabelecimento inicial da cultura de soja (Timossi e Durigan 2006). A sua ação residual pode ser influenciada pela textura do solo, como foi observado por Takano et al. (2015), que observaram diferentes controles na emergência da planta daninha Senna obtusifolia.

Este herbicida atende às propriedades atualmente esperadas para um defensivo agrícola, que inclui a sua rápida degradação, eficiência em doses baixas, especificidade e baixa toxicidade para os organismos não alvo (Monteiro, 2001). Gupta (2007), relata a baixa toxidez do diclosulam. Sua aplicação pode causar sintomas visuais de injúrias distintas em diferentes cultivares de soja (Barros et al., 2005), tais como menor velocidade de emergência das plântulas, desenvolvimento reduzido e menor porte vegetativo. Esses distúrbios podem resultar em menor produtividade de grãos.

Sabe-se que a tolerância de cultivares de uma mesma espécie, inclusive a soja, respondem de forma diferente ao estresse causado pelos herbicidas, em razão de suas diferenças genotípicas (Velini et al., 1993; Lima et al., 2011). Desta forma, o uso deste tipo de herbicida pode promover a redução da interferência de plantas daninhas no início do ciclo de desenvolvimento da cultura, contribuindo para o fechamento mais efetivo e precoce da soja (Jaremtchuk et al., 2008, Oliveira Neto et al., 2013).

Portanto, é necessário que se realize estudos de sensibilidade e/ou seletividade em novos materiais de soja disponíveis no mercado. Neste contexto, objetivou-se avaliar a 
sensibilidade de três cultivares de soja cultivadas em solos de textura argilosa e média submetidos à aplicação do herbicida diclosulam.

\section{Material e Métodos}

Os trabalhos foram conduzidos em casa de vegetação durante os meses de março a junho de 2016. As condições climáticas médias no período em que os experimentos foram realizados foram temperatura de $22^{\circ} \mathrm{C}$ e umidade relativa do ar em $65 \%$.

Realizaram-se três experimentos para avaliar a sensibilidade de diferentes cultivares de soja ao herbicida diclosulam (Spider ${ }^{\circledR} 840$ WG, $840 \mathrm{~g} \mathrm{~kg}^{-1}$, Dow AgroSciences), sendo adotado um experimento para cada cultivar. Os ensaios foram instalados em delineamento inteiramente casualizado com quatro repetições. Para os três experimentos, adotou-se o esquema fatorial $6 \times 2$, em que o fator A correspondeu a diferentes épocas de aplicação do herbicida diclosulam $(28,21,14,7$ e 0 dias antes da semeadura (DAS) e testemunha sem aplicação) e o fator B correspondeu a textura do solo (argilosa e média).

Nos três experimentos foram utilizados vasos com capacidade para 2 litros,devidamente preenchidos com solos de texturas distintas, sendo cada vaso uma unidade experimental. $\mathrm{O}$ solo de textura argilosa apresentou as seguintes características físico/químicas: 553, 201 e 246 $\mathrm{gdm}^{-3}$ de argila, silte e areia, respectivamente; $\mathrm{pH}\left(\mathrm{CaCl}_{2}\right)=4,8 ;$ M.O. $=23 \mathrm{~g} \mathrm{dm}^{-3} ; \mathrm{P}$ (resina) $=16 \mathrm{mg} \mathrm{dm}^{-3} ; \mathrm{Al}^{3+}=2 \mathrm{mmol}_{\mathrm{c}} \mathrm{dm}^{-3} ; \mathrm{H}+\mathrm{Al}=48$ mmolc dm ${ }^{-3} ; \mathrm{K}+=1,3$ mmolc dm ${ }^{-3} ; \mathrm{Ca}^{2+}=23$ mmolc dm ${ }^{-3} ; \mathrm{Mg}^{2+}=10$ mmolc dm ${ }^{-3} ; \mathrm{SB}=34$ mmolc dm ${ }^{-3} ;$ CTC $(\mathrm{T})=83$ mmolc dm ${ }^{-3} ; \mathrm{S}=56$ $\mathrm{mg} \mathrm{dm}{ }^{-3} \mathrm{e} \mathrm{V \%}=41$. Já o solo com textura média apresentou as seguintes características: 281,87 e $632 \mathrm{gdm}^{-3}$ de argila, silte e areia, respectivamente; $\mathrm{pH}\left(\mathrm{CaCl}_{2}\right)=5,3 ;$ M.O. $=11 \mathrm{~g}$ $\mathrm{dm}^{-3} ; \mathrm{P}($ resina $)=18 \mathrm{mg} \mathrm{dm}^{-3} ; \mathrm{Al}^{3+}=1 \mathrm{mmolc}$ $\mathrm{dm}^{-3} ; \mathrm{H}+\mathrm{Al}=39$ mmolc dm ${ }^{-3} ; \mathrm{K}+=0,8$ mmolc $\mathrm{dm}^{-3} ; \mathrm{Ca}^{2+}=21$ mmolc dm ${ }^{-3} ; \mathrm{Mg}^{2+}=11$ mmolc $\mathrm{dm}^{-3} ; \mathrm{SB}=32$ mmolc $\mathrm{dm}^{-3} ;$ CTC $(\mathrm{T})=71$ mmolc dm ${ }^{-3} ; \mathrm{S}=38 \mathrm{mg} \mathrm{dm}^{-3}$ e $\mathrm{V} \%=46$.
Para a aplicaçãodo diclosulam, na dosagem de $35 \mathrm{~g} \mathrm{ha}^{-1}$ de i.a., que ocorreusobre solos úmidos, utilizou-se um pulverizador estacionário constituído por estrutura metálica (barra de pulverização) com 2 metros de largura, tracionada por um conjunto de motor elétrico e modulador de frequência, tornando possível o controle da velocidade de trabalho. Esta barra foi composta por quatro pontas de pulverização XR 110.02 VS, espaçadas em $0,5 \mathrm{~m}$ e dispostas a 0,5 $m$ de altura em relação às unidades experimentais. A pressão de trabalho utilizada no equipamento foi de $196,13 \mathrm{kPa}$, com velocidade de $3,6 \mathrm{~km} \mathrm{~h}^{-1} \mathrm{e}$ consumo de calda de $200 \mathrm{~L} \mathrm{ha}^{-1}$.

As aplicações ocorreram aos 28, 21, 14, 7 e 0 dias antes da semeadura (DAS) da soja. As cultivares utilizadas foram a Monsoy M 6410 IPRO, Nidera NS 6906 IPRO e Nidera NS 7000 IPRO, ambas tratadas com piraclostrobina + tiofanato metílico + fipronil (Standak ${ }^{\circledR}$ Top, 25 $\mathrm{g} \mathrm{L}^{-1}+225 \mathrm{~g} \mathrm{~L}^{-1}+250 \mathrm{~g} \mathrm{~L}^{-1}$, Basf) na dosagem de $50 \mathrm{~g} \mathrm{ha}^{-1}$ de i.a.

A semeadura das cultivares foi realizada com 4 sementes por vaso e à $3 \mathrm{~cm}$ de profundidade em ambos os solos. No ato da semeadura, todos os vasos receberam uma lâmina de água de $10 \mathrm{~mm}^{-1}$ para que o herbicida fosse posicionado na camada de germinação das sementes.

Avaliou-se o índice de velocidade de emergência (IVE), porcentagem de fitotoxicidade, altura de plantas, massa seca de parte aérea e de raiz. Para determinação do IVE, diariamente foi registrado o número de plântulas emergidas, com parte aérea formada, até a estabilização da emergência, e este foi calculado pela fórmula proposta por Maguire (1962):

$$
\mathrm{IVE}=\mathrm{E} 1 / \mathrm{N} 1+\mathrm{E} 2 / \mathrm{N} 2+\ldots \mathrm{En} / \mathrm{Nn}
$$

Onde: IVE = índice de velocidade de emergência. E1, E2, ...En = Número de plântulas normais computadas na primeira, segunda e última contagem. $\mathrm{N} 1, \mathrm{~N} 2, \ldots \mathrm{Nn}=$ número de dias da semeadura à primeira, segunda e última contagem. 
As avaliações de altura das plantas foram realizadas aos 14 e 28 dias após a emergência (DAE) medindo-se, da base do caule rente ao solo até a última inserção foliar. Nestes mesmos períodos foram efetuadas as avaliações de fitotoxicidade, adotando-se a escala visual de 0 a $100 \%$, onde 0 representa ausência de sintomas e $100 \%$ morte das plantas.

A massa seca da parte aérea e do sistema radicular foram quantificadas aos 28 DAE. O material vegetal foi encaminhado à estufa de circulação forçada de ar a $65^{\circ} \mathrm{C}$ até obtenção de massa constante.

Os dados, com exceção da escala visual de sintomas, foram submetidos à análise de variância pelo teste $\mathrm{F}$ e as médias comparadas pelo teste de Tukey à 5\% de probabilidade.

\section{Resultados e Discussão}

Para a cultivar M 6410 IPRO, tanto as épocas de aplicação quanto as texturas dos solos não influenciaram no índice de velocidade de emergência (IVE) das plântulas, porém, ao analisar as cultivares NS 6906 IPRO e NS 7000 IPRO, o IVE foi estatisticamente superior à testemunha nos tratamentos que receberam aplicações de diclosulam aos 21 e 28 dias antes da semeadura (DAS) no solo argiloso, no entanto, ao se fazer a comparação entre estes solos, a textura não influenciou neste parâmetro (Tabela 1). Estes dados obtidos foram diferentes dos encontrados por Barros et al. (2005), que ao estudar a tolerância de cultivares de soja ao herbicida diclosulam, aplicados em solo de textura arenosa, observaram que os genótipos tiveram comportamento diferenciado. Isso demonstra que os genótipos utilizados no presente trabalho foram tolerantes ao herbicida, e reforça a ideia de que genótipos de mesma espécie respondem de forma diferente à produtos químicos aplicados.

Ao analisar a altura média das plantas aos 14 dias após a emergência (DAE), a cultivar M 6410 IPRO não respondeu aos efeitos dos tratamentos (Tabela 2). Já a cultivar NS 7000 IPRO, ao se comparar as épocas de semeadura, no solo argiloso aos 21 e 28 DAS a altura de plantas foi maior que a testemunha. A cultivar NS 6906 IPRO não apresentou diferença significativa na altura de plantas quando feita comparação entre as texturas dos solos. Ao realizar a comparação entre as épocas, aos 21 DAS e 28 DAS as plantas desta cultivar foram maiores em relação à testemunha.

Tabela 1. Índice de velocidade de emergência (IVE) de plântulas de três cultivares de soja cultivadas em solos de textura argilosa e média, após receberem aplicação do herbicida diclosulam em diferentes épocas. Botucatu (SP), 2016.

\begin{tabular}{|c|c|c|c|c|c|c|}
\hline \multirow{3}{*}{ Épocas de aplicação } & \multicolumn{6}{|c|}{ IVE } \\
\hline & \multicolumn{2}{|c|}{ M 6410 IPRO } & \multicolumn{2}{|c|}{ NS 6906 IPRO } & \multicolumn{2}{|c|}{ NS 7000 IPRO } \\
\hline & Argilosa & Média & Argilosa & Média & Argilosa & Média \\
\hline Testemunha & 0,69 aA & $0,98 \mathrm{aA}$ & $1,08 \mathrm{bB}$ & $1,47 \mathrm{aA}$ & $0,92 \mathrm{cA}$ & $1,15 \mathrm{aA}$ \\
\hline 0 DAS & $0,67 \mathrm{aA}$ & $0,89 \mathrm{aA}$ & $1,26 \mathrm{abA}$ & $1,27 \mathrm{aA}$ & $0,91 \mathrm{bcA}$ & $1,02 \mathrm{aA}$ \\
\hline 7 DAS & $1,06 \mathrm{aA}$ & $0,69 \mathrm{aA}$ & $1,30 \mathrm{abA}$ & $1,48 \mathrm{aA}$ & $1,30 \mathrm{abA}$ & $1,02 \mathrm{aA}$ \\
\hline 14 DAS & $1,05 \mathrm{aA}$ & $0,89 \mathrm{aA}$ & $1,27 \mathrm{abA}$ & $1,34 \mathrm{aA}$ & $1,17 \mathrm{abcA}$ & $1,02 \mathrm{aA}$ \\
\hline 21 DAS & $0,88 \mathrm{aA}$ & $0,92 \mathrm{aA}$ & $1,51 \mathrm{aA}$ & $1,37 \mathrm{aA}$ & $1,32 \mathrm{aA}$ & $0,96 \mathrm{aA}$ \\
\hline 28 DAS & $1,07 \mathrm{aA}$ & $0,89 \mathrm{aA}$ & $1,44 \mathrm{aA}$ & $1,26 \mathrm{aA}$ & $1,40 \mathrm{aA}$ & $1,12 \mathrm{aA}$ \\
\hline F aplicação & \multicolumn{2}{|c|}{$0,42^{\mathrm{ns}}$} & \multicolumn{2}{|c|}{$1,99^{\mathrm{ns}}$} & \multicolumn{2}{|c|}{$2,33^{\mathrm{ns}}$} \\
\hline F solo & \multicolumn{2}{|c|}{$0,08^{\mathrm{ns}}$} & \multicolumn{2}{|c|}{$0,69^{\text {ns }}$} & \multicolumn{2}{|c|}{$2,60^{\mathrm{ns}}$} \\
\hline $\mathrm{FA} \times \mathrm{S}$ & \multirow{2}{*}{\multicolumn{2}{|c|}{$\begin{array}{l}1,17^{\mathrm{ns}} \\
3718\end{array}$}} & \multicolumn{2}{|c|}{$2,62^{*}$} & \multicolumn{2}{|c|}{$3,08^{*}$} \\
\hline $\mathrm{CV}(\%)$ & & & \multicolumn{2}{|c|}{11,81} & \multicolumn{2}{|c|}{18,85} \\
\hline
\end{tabular}

DAS = dias antes da semeadura; ${ }^{\text {ns }}$ não significativo, ${ }^{*}$ significativo à $5 \%$ de probabilidade pelo teste de $\mathrm{F}$. Médias seguidas da mesma letra, minúscula na coluna e maiúscula na linha, para cada cultivar, não diferem significativamente pelo teste de Tukey $(\mathrm{p} \geq 0,05)$. 
Tabela 2. Altura média de plantas de três cultivares de soja aos 14 dias após a emergência (DAE), cultivadas em solos de textura argilosa e média após receberem aplicação do herbicida diclosulam em diferentes épocas. Botucatu (SP), 2016.

\begin{tabular}{|c|c|c|c|c|c|c|}
\hline \multirow{3}{*}{ Épocas de aplicação } & \multicolumn{6}{|c|}{ Altura de plantas $\left(\mathrm{cm}^{-1}\right)$} \\
\hline & \multicolumn{2}{|c|}{ M 6410 IPRO } & \multicolumn{2}{|c|}{ NS 6906 IPRO } & \multicolumn{2}{|c|}{ NS 7000 IPRO } \\
\hline & Argilosa & Média & Argilosa & Média & Argilosa & Média \\
\hline Testemunha & $4,66 \mathrm{aA}$ & $4,82 \mathrm{aA}$ & $5,84 \mathrm{bA}$ & $6,87 \mathrm{bA}$ & $3,17 \mathrm{bB}$ & $4,37 \mathrm{aA}$ \\
\hline 0 DAS* & $4,12 \mathrm{aA}$ & $4,94 \mathrm{aA}$ & 7,03 abA & $7,18 \mathrm{abA}$ & $3,07 \mathrm{bB}$ & $4,18 \mathrm{aA}$ \\
\hline 7 DAS & $4,61 \mathrm{aA}$ & $4,62 \mathrm{aA}$ & $7,18 \mathrm{abA}$ & $7,78 \mathrm{abA}$ & $4,25 \mathrm{abA}$ & $4,32 \mathrm{aA}$ \\
\hline 14 DAS & $5,31 \mathrm{aA}$ & $5,80 \mathrm{aA}$ & 7,00 abA & $7,71 \mathrm{abA}$ & $4,28 \mathrm{abA}$ & $4,19 \mathrm{aA}$ \\
\hline $21 \mathrm{DAS}$ & $5,00 \mathrm{aA}$ & $5,15 \mathrm{aA}$ & $8,21 \mathrm{aA}$ & 8,46 aA & $4,90 \mathrm{aA}$ & $4,61 \mathrm{aA}$ \\
\hline 28 DAS & $5,18 \mathrm{aA}$ & $5,58 \mathrm{aA}$ & $8,68 \mathrm{aA}$ & $9,15 \mathrm{aA}$ & 5,18 aA & $4,68 \mathrm{aA}$ \\
\hline F aplicação & \multicolumn{2}{|c|}{$1,76^{\mathrm{ns}}$} & \multicolumn{2}{|c|}{$4,98 * *$} & \multicolumn{2}{|c|}{$3,71 * *$} \\
\hline F solo & \multicolumn{2}{|c|}{$1,70^{\mathrm{ns}}$} & \multicolumn{2}{|c|}{$3,66^{\mathrm{ns}}$} & \multicolumn{2}{|c|}{$1,42^{\mathrm{ns}}$} \\
\hline $\mathrm{F} A \times \mathrm{S}$ & \multicolumn{2}{|c|}{$0,21^{\mathrm{ns}}$} & \multicolumn{2}{|c|}{$2,27^{\mathrm{ns}}$} & \multicolumn{2}{|c|}{$2,26^{\mathrm{ns}}$} \\
\hline $\mathrm{CV}(\%)$ & \multicolumn{2}{|c|}{18,04} & \multicolumn{2}{|c|}{12,79} & \multicolumn{2}{|c|}{17,14} \\
\hline
\end{tabular}

DAS = dias antes da semeadura ${ }^{\text {ns }}$ não significativo, $* *$ significativo à $1 \%$ de probabilidade pelo teste de F. Médias seguidas da mesma letra, minúscula na coluna e maiúscula na linha, para cada cultivar, não diferem significativamente pelo teste de Tukey $(p \geq 0,05)$.

Aos 28 DAE, tanto as épocas quanto as texturas dos solos não exerceram influência na cultivar M 6410 IPRO para o parâmetro analisado (Tabela 3). Já para a cultivar NS 6906 IPRO semeada em solo argiloso, todos as épocas, com exceção de 0 DAS, proporcionaram plantas de maior altura aos 28 DAE, no entanto, quando a semeadura ocorreu no solo de textura média somente houve diferença significativa quando a aplicação do diclosulam ocorreu aos 14, 21 e 28 DAS. Para esta mesma cultivar, ao fazer a comparação entre os solos estudados, não foi observado diferença significativa na altura média de plantas. Segundo Timossi e Durigan (2002), a altura e a arquitetura das plantas de uma determinada cultivar de soja são importantes para o fechamento das entrelinhas da cultura e consequente sombreamento do solo, evitando assim a germinação de sementes e o estabelecimento de várias espécies de plantas daninhas.

Estes dados estão em desacordo com os encontrados por Barros et al. (2005), que verificou desenvolvimento reduzido e menor porte vegetativo de algumas cultivares de soja (GOIÂNIA, GOBR 93-122243 RNC e LUZIÂNIA; GOBR 93-122243 RCN, GOIÂNIA, LUZIANIA, EMGOPA 316, SANTA CRUZ e CRIXÁS) em solos tratados com este mesmo herbicida. No entanto, a cultivar NS 7000 IPRO quando cultivada em solo argiloso, apresentou maior altura média de plantas aos 7, 14, 21 e 28 DAE; já para esta mesma cultivar semeada em solo de textura média, esse aumento na altura das plantas só ocorreu quando a aplicação do herbicida aconteceu aos 21 e 28 DAS (Tabela 3). Ao se fazer a comparação entre os solos, no de textura argilosa aos 0,7 e 28 DAS a altura média de plantas foi menor. Estas diferenças entre os solos podem ser explicadas pelo fato do solo de textura média apresentar maior $\mathrm{pH}$ e V\%.

Estes resultados estão de acordo com Leite et al. (2000), que ao estudarem a sensibilidade de 12 cultivares de soja aos herbicidas diclosulam e flumetsulam aplicados em solo com 80,84\% de argila e 3,07\% de matéria orgânica, relataram que a altura das plantas foi aumentada com a aplicação de diclosulam e as médias gerais de biomassa da parte aérea e de raízes foram superiores à testemunha. Além disso, houve correspondência entre a maior altura observada e a produção. Ainda segundo Leite et al. (2000), a detoxificação do diclosulam em soja podem ser pela hidroxilação seguida de conjugação com glicose e/ou conjugação com homoglutationa. Então, espera-se que cultivares de soja com 
semelhantes mecanismos podem tolerar melhor estes herbicidas.

Já Osipe et al. (2014), observaram níveis de fitointoxicação e redução na altura de plantas de soja tratadas com diclosulam. No entanto, a produtividade da soja não foi afetada, o que pode tornar a utilização deste produto uma excelente ferramenta dentro de sistemas de aplicação de herbicidas em pré-emergência desta cultura. Outro fator importante para a seletividade deste herbicida na cultura da soja está ligado ao seu comportamento no solo, pois o diclosulam é fortemente influenciado pelos teores de umidade e matéria orgânica; a degradação é microbiana, e a fotodegradação e volatilização são insignificantes (Rodrigues e Almeida, 2011).

Tabela 3. Altura média de plantas de três cultivares de soja aos 28 dias após a emergência, cultivadas em solos de texturas argilosa e média após receberem aplicação do herbicida diclosulam em diferentes épocas. Botucatu (SP), 2016.

\begin{tabular}{|c|c|c|c|c|c|c|}
\hline \multirow{3}{*}{ Épocas de semeadura } & \multicolumn{6}{|c|}{ Altura de plantas $\left(\mathrm{cm}^{-1}\right)$} \\
\hline & \multicolumn{2}{|c|}{ M 6410 IPRO } & \multicolumn{2}{|c|}{ NS 6906 IPRO } & \multicolumn{2}{|c|}{ NS 7000 IPRO } \\
\hline & Argilosa & Média & Argilosa & Média & Argilosa & Média \\
\hline Testemunha & $9,39 \mathrm{aA}$ & $9,78 \mathrm{aA}$ & $11,71 \mathrm{bA}$ & $12,15 \mathrm{cA}$ & $8,97 \mathrm{bA}$ & $8,50 \mathrm{cA}$ \\
\hline 0 DAS* & $11,43 \mathrm{aA}$ & 9,95 aA & $14,28 \mathrm{abA}$ & $12,95 \mathrm{cA}$ & $8,50 \mathrm{bB}$ & $9,89 \mathrm{bcA}$ \\
\hline 7 DAS & $10,02 \mathrm{aA}$ & $10,54 \mathrm{aA}$ & $14,71 \mathrm{aA}$ & $14,09 \mathrm{bcA}$ & $10,60 \mathrm{aB}$ & $11,15 \mathrm{bA}$ \\
\hline 14 DAS & $11,15 \mathrm{aA}$ & 11,43 aA & 15,95 aA & $16,00 \mathrm{abA}$ & $11,21 \mathrm{aA}$ & $11,11 \mathrm{bA}$ \\
\hline 21 DAS & $10,31 \mathrm{aA}$ & $11,56 \mathrm{aA}$ & 15,59 aA & $16,03 \mathrm{abA}$ & $12,05 \mathrm{aA}$ & $12,21 \mathrm{aA}$ \\
\hline $28 \mathrm{DAS}$ & $10,47 \mathrm{aA}$ & $10,58 \mathrm{aA}$ & 16,25 aA & $16,83 \mathrm{aA}$ & $12,31 \mathrm{aB}$ & $13,90 \mathrm{aA}$ \\
\hline F aplicação & \multicolumn{2}{|c|}{$1,51^{\mathrm{ns}}$} & \multicolumn{2}{|c|}{$16,36^{* *}$} & \multicolumn{2}{|c|}{$23,09^{* *}$} \\
\hline F solo & \multicolumn{2}{|c|}{$0,21^{\mathrm{ns}}$} & \multicolumn{2}{|c|}{$0,05^{\mathrm{ns}}$} & \multicolumn{2}{|c|}{$0,00^{\mathrm{ns}}$} \\
\hline $\mathrm{FA} \times \mathrm{S}$ & \multirow{2}{*}{\multicolumn{2}{|c|}{$0,89^{\text {ns }}$}} & \multicolumn{2}{|c|}{$1,07^{\mathrm{ns}}$} & \multicolumn{2}{|c|}{$3,57^{*}$} \\
\hline CV $(\%)$ & & 12,83 & \multicolumn{2}{|c|}{8,19} & \multicolumn{2}{|c|}{8,81} \\
\hline
\end{tabular}

DAS = dias antes da semeadura; ${ }^{\text {ns }}$ não significativo, ${ }^{*} \mathrm{e}^{* *}$ significativo à 5 e $1 \%$ de probabilidade, respectivamente, pelo teste de $\mathrm{F}$. Médias seguidas da mesma letra, minúscula na coluna e maiúscula na linha, para cada cultivar, não diferem significativamente pelo teste de Tukey ( $\mathrm{p} \geq 0,05)$.

Em relação à massa seca da parte aérea (MSPA), não foi observada diferença estatística para a cultivar M 6410 IPRO (Tabela 4). Na cultivar NS 6906 IPRO, só foi observado maior MSPA quando a semeadura foi feita em solo de textura média e nas épocas que receberam a aplicação de diclosulam aos 28 DAS. A cultivar NS 7000 IPRO não respondeu às épocas, somente foi observada diferença significativa quando foi realizada a comparação entre os solos. Neste caso, plantas da testemunha e do tratamento 0 DAS semeadas no solo argiloso, apresentaram menor MSPA.

Para a comparação entre os tipos de solos, a cultivar M 6410 IPRO apresentou menor rendimento no argiloso, na testemunha e quando a aplicação do herbicida ocorreu aos 28 DAS (Tabela 5). A cultivar NS 6906 IPRO apresentou maior massa de raiz no solo de textura média em todas as épocas, com exceção dos 28 DAS. Já na cultivar NS 7000 IPRO, a massa seca de raiz foi semelhante em ambos os solos, sendo inferior apenas na testemunha e aos 0 DAS no argiloso.

Os resultados de fitotoxicidade não foram apresentados, pois não foi observado sintomas visuais nas cultivares avaliadas durante a condução do experimento. Estes resultados estão de acordo com Deuber e Novo (2006), que não verificaram injúrias visíveis nas plantas de soja quando o diclosulam foi aplicado em pré-emergência, em solos de textura arenobarrenta e argilosa. Entretanto, a seletividade do herbicida diclosulam $\left(35,28 \mathrm{~g} \mathrm{ha}^{-1}\right)$ aplicado em pré-emergência para a cultura da soja foi avaliada por Biffe (2012) em solo de textura argilosa, e reduções no rendimento de grãos foram observadas, principalmente em solos com problemas de compactação. 
Tabela 4. Massa seca da parte aérea (MSPA) de plantas de três cultivares de soja cultivadas em solos de texturas argilosa e média, após receberem aplicação do herbicida diclosulam em diferentes épocas. Botucatu (SP), 2016.

\begin{tabular}{|c|c|c|c|c|c|c|}
\hline \multirow{3}{*}{ Épocas de semeadura } & \multicolumn{6}{|c|}{$\operatorname{MSPA}\left(\mathrm{gr}^{-1}\right)$} \\
\hline & \multicolumn{2}{|c|}{ M 6410 IPRO } & \multicolumn{2}{|c|}{ NS 6906 IPRO } & \multicolumn{2}{|c|}{ NS 7000 IPRO } \\
\hline & Argilosa & Média & Argilosa & Média & Argilosa & Média \\
\hline Testemunha & $0,69 \mathrm{aA}$ & $1,02 \mathrm{aA}$ & $1,36 \mathrm{aA}$ & $1,54 \mathrm{bA}$ & $0,94 \mathrm{aB}$ & $1,43 \mathrm{aA}$ \\
\hline $0 \mathrm{DAS}^{*}$ & $0,67 \mathrm{aA}$ & $0,87 \mathrm{aA}$ & $1,42 \mathrm{aA}$ & $1,72 \mathrm{bA}$ & $0,98 \mathrm{aB}$ & $1,59 \mathrm{aA}$ \\
\hline 7 DAS & $0,92 \mathrm{aA}$ & $0,83 \mathrm{aA}$ & $1,58 \mathrm{aA}$ & $1,71 \mathrm{bA}$ & $1,43 \mathrm{aA}$ & $1,49 \mathrm{aA}$ \\
\hline 14 DAS & $0,92 \mathrm{aA}$ & $0,86 \mathrm{aA}$ & $1,52 \mathrm{aA}$ & $1,81 \mathrm{bA}$ & $1,41 \mathrm{aA}$ & $1,60 \mathrm{aA}$ \\
\hline $21 \mathrm{DAS}$ & $0,63 \mathrm{aA}$ & $0,90 \mathrm{aA}$ & $1,61 \mathrm{aA}$ & $1,87 \mathrm{abA}$ & $1,40 \mathrm{aA}$ & $1,45 \mathrm{aA}$ \\
\hline 28 DAS & $0,66 \mathrm{aA}$ & $0,92 \mathrm{aA}$ & $1,54 \mathrm{aA}$ & $2,36 \mathrm{aA}$ & $1,49 \mathrm{aA}$ & $1,68 \mathrm{aA}$ \\
\hline F aplicação & \multicolumn{2}{|c|}{$0,29^{\mathrm{ns}}$} & \multicolumn{2}{|c|}{$3,90 * *$} & \multicolumn{2}{|c|}{$2,42^{\mathrm{ns}}$} \\
\hline F solo & \multicolumn{2}{|c|}{$3,22^{\text {ns }}$} & \multicolumn{2}{|c|}{$20,19 * *$} & \multicolumn{2}{|c|}{$11,68 * *$} \\
\hline $\mathrm{F} A \times \mathrm{S}$ & \multicolumn{2}{|c|}{$0,74^{\mathrm{ns}}$} & \multicolumn{2}{|c|}{$1,49^{\mathrm{ns}}$} & \multicolumn{2}{|c|}{$1,57^{\mathrm{ns}}$} \\
\hline $\mathrm{CV}(\%)$ & \multicolumn{2}{|c|}{35,73} & \multicolumn{2}{|c|}{15,21} & \multicolumn{2}{|c|}{18,73} \\
\hline
\end{tabular}

DAS = dias antes da semeadura; ${ }^{\text {ns }}$ não significativo, ${ }^{* *}$ significativo à $1 \%$ de probabilidade pelo teste de F. Médias seguidas da mesma letra, minúscula na coluna e maiúscula na linha, para cada cultivar, não diferem significativamente pelo teste de Tukey $(p \geq 0,05)$.

Tabela 5. Massa seca de raiz (MSR) de plantas em três cultivares de soja cultivadas em solos de texturas argilosa e média, após receberem aplicação do herbicida diclosulam em diferentes épocas. Botucatu (SP), 2016.

\begin{tabular}{|c|c|c|c|c|c|c|}
\hline \multirow{3}{*}{ Épocas de semeadura } & \multicolumn{6}{|c|}{$\operatorname{MSR}\left(\mathrm{gr}^{-1}\right)$} \\
\hline & \multicolumn{2}{|c|}{ M 6410 IPRO } & \multicolumn{2}{|c|}{ NS 6906 IPRO } & \multicolumn{2}{|c|}{ NS 7000 IPRO } \\
\hline & Argiloso & Médio & Argiloso & Médio & Argiloso & Médio \\
\hline Testemunha & $0,21 \mathrm{aB}$ & $0,87 \mathrm{aA}$ & $0,37 \mathrm{aB}$ & $0,99 \mathrm{aA}$ & $0,41 \mathrm{aB}$ & $1,36 \mathrm{aA}$ \\
\hline 0 DAS $*$ & $0,42 \mathrm{aA}$ & $0,62 \mathrm{abA}$ & $0,46 \mathrm{aB}$ & $1,49 \mathrm{aA}$ & $0,34 \mathrm{aB}$ & $1,18 \mathrm{aA}$ \\
\hline 7 DAS & $0,26 \mathrm{aA}$ & $0,49 \mathrm{abA}$ & $0,44 \mathrm{aB}$ & $1,71 \mathrm{aA}$ & $0,54 \mathrm{aA}$ & $1,09 \mathrm{aA}$ \\
\hline 14 DAS & $0,33 \mathrm{aA}$ & $0,41 \mathrm{abA}$ & $0,44 \mathrm{aB}$ & $1,53 \mathrm{aA}$ & $0,62 \mathrm{aA}$ & $1,08 \mathrm{aA}$ \\
\hline $21 \mathrm{DAS}$ & $0,21 \mathrm{aA}$ & $0,43 \mathrm{abA}$ & $0,85 \mathrm{aB}$ & $1,67 \mathrm{aA}$ & $0,61 \mathrm{aA}$ & $0,75 \mathrm{aA}$ \\
\hline $28 \mathrm{DAS}$ & $0,20 \mathrm{aB}$ & $0,76 \mathrm{abA}$ & $0,89 \mathrm{aA}$ & $1,32 \mathrm{aA}$ & $0,78 \mathrm{aA}$ & $0,96 \mathrm{aA}$ \\
\hline F aplicação & \multicolumn{2}{|c|}{$1,54^{\mathrm{ns}}$} & \multicolumn{2}{|c|}{$1,75^{\mathrm{ns}}$} & \multicolumn{2}{|c|}{$0,24^{\mathrm{ns}}$} \\
\hline F solos & \multicolumn{2}{|c|}{$29,94 * *$} & \multicolumn{2}{|c|}{$54,39 * *$} & \multicolumn{2}{|c|}{$16,35 * *$} \\
\hline $\mathrm{FA} \times \mathrm{S}$ & \multicolumn{2}{|c|}{$2,42^{\mathrm{ns}}$} & \multicolumn{2}{|c|}{$1,16^{\mathrm{ns}}$} & \multicolumn{2}{|c|}{$1,12^{\text {ns }}$} \\
\hline $\mathrm{CV}(\%)$ & \multicolumn{2}{|c|}{47,16} & \multicolumn{2}{|c|}{40,39} & \multicolumn{2}{|c|}{54,65} \\
\hline
\end{tabular}

DAS = dias antes da semeadura; Trat $=$ tratamentos. ${ }^{\text {ns }}$ não significativo, ${ }^{* *}$ significativo à $1 \%$ de probabilidade pelo teste de $\mathrm{F}$. Médias seguidas da mesma letra, minúscula na coluna e maiúscula na linha não diferiram significativamente pelo teste de Tukey $(\mathrm{p} \geq 0,05)$.

Embora não se tenham encontrados sintomas de fitotoxicidade na cultura avaliada, é importante ressaltar que é cada vez mais comum o plantio de cultivares de soja com ciclo precoce e superprecoce associada a técnicas para antecipação de colheita. Estas ações reduzem o intervalo de tempo entre a aplicação de herbicidas na cultura da soja e a semeadura da cultura subsequente, o que aumenta os riscos de um eventual efeito negativo promovido pelo resíduo de alguns herbicidas sobre culturas em sucessão. Fato este relatado por Dan et al. (2012), que ao estudarem os efeitos residuais de herbicidas utilizados na cultura da soja sobre o milho cultivado em sucessão, observaram sinais de injúrias e redução na altura das plantas cultivadas aos 115 dias após a aplicação do herbicida diclosulam. Enquanto que Dan et al. (2010), constataram efeitos negativos do herbicida diclosulam em plantas de sorgo cultivados em sucessão à soja em região de Cerrado.

Tais efeitos negativos são causados pela inibição da atividade da enzima acetolactato sintase (ALS). Segundo Tan et al. (2006), plantas altamente sensíveis podem apresentar 
paralisação do crescimento apical em função da redução da biossíntese de valina, leucina e isoleucina, aminoácidos essenciais ao desenvolvimento da planta. Entretanto, os efeitos secundários benéficos observados no presente trabalho precisam ser melhores estudados e compreendidos pela pesquisa.

\section{Conclusões}

O herbicida diclosulam utilizado em préemergência nos solos de textura argilosa e média é seguro para as cultivares de soja analisadas.

\section{Referências}

Barros, A.C.; Monteiro, P.M.F.O.; Furtado, X.C.; Nunes Júnior, J.; Guerzoni, R.A. Tolerância de cultivares de soja aos herbicidas imazaquin, diclosulam e sulfentrazone, aplicados em solo de textura arenosa. Revista Brasileira de Herbicidas, v.4, n.1, p.01-08, 2005.

Biffe, D.F. Efeito da aplicação de herbicidas em pré-emergência e de glyphosate em pósemergência sobre a cultura da soja $R R$, em solo compactado e não compactado. 2012. 104 f. Tese (Doutorado em Agronomia) Universidade Estadual de Maringá, 2012.

CONAB - Companhia Nacional de Abastecimento. Acompanhamento da safra brasileira de grãos, v.8 - Safra 2015/16. Oitavo levantamento, p.1-178, maio 2016.

Dan, H.A.; Dan, L.G.M.; Barroso, A.L.L.; Procópio, S.O.; Oliveira Jr., R.S.; Silva, A.G. et al. Residual activity of herbicides used in soybean agriculture on grain sorghum crop succession. Planta Daninha, v.28, n.5, p.10871095, 2010.

Dan, H.A.; Dan, L.G.M.; Barroso, A.L.L.; Oliveira Neto, A.M.; Guerra, N. Resíduos de herbicidas utilizados na cultura da soja sobre o milho cultivado em sucessão. Revista Caatinga, v.25, n.1, p.86-91, 2012.
Deuber, R.; Novo, M.C.S.S. Nodulação e desenvolvimento de planta de soja IAC-19 com aplicação dos herbicidas diclosulam e flumetsulam. Revista Brasileira de Herbicidas, v.5, n.2, p.57-63, 2006.

Fleck, N.G.; Vidal, R.A. Injúria potencial de herbicidas de solo no girassol. III Imazaquin e Imazethapyr. Planta Daninha, v.12, n.1, p.3943, 1994.

Gupta, P.K. Toxicity of herbicides. In: Gupta, R.C. Veterinary toxicology. USA, KY: Murray State University, p.567-586, 2007.

Jaremtchuk, C.C.; Constantin, J.; Oliveira Jr., R.S.; Biffe, D.F.; Alonso, D.G.; Arantes, J.G.Z. Efeito de sistemas de manejo sobre a velocidade de dessecação, infestação inicial de plantas daninhas e desenvolvimento e produtividade da soja. Acta Scientiarum. Agronomy, v.30, n.4, p.449-455, 2008.

Leite, C.R.F.; Almeida, C.V.; Prete, C.E.C. Sensibilidade de cultivares de soja (Glycine max) aos herbicidas diclosulam e flumetsulam.

Planta Daninha, v.18, n.1, p.103-122, 2000.

Lima, D.B.C.; Silva, A.G.; Procópio, S.O.; Barroso, A.L.L.; Dan, H.A.; Costa, E.B. et al. Seleção de herbicidas para o controle de plantas voluntárias de soja resistentes ao glyphosate. Revista Brasileira de Herbicidas, v.10, n.1, p.01-12, 2011.

Maguire, J.D. Speed of germination-aid in selection and evaluation for seedling emergence and vigor. Crop Science, v.2, n.1, p.176-177, 1962.

Monteiro, R.T.R. Biodegradação de pesticidas em solos brasileiros. In: Melo, I.S. Biodegradação. Jaguariúna: Embrapa Meio Ambiente, p.1-28, 2001.

Oliveira Neto, A.M.; Constantin, J.; Oliveira Jr., R.S.; Guerra, N.; Braz, G.B.P.; Vilela, L.M.S.; Botelho, L.V.P.; Ávila, L.A. Sistemas de dessecação em áreas de trigo no inverno e atividade residual de herbicidas na soja. Revista 
Brasileira de Herbicidas, v.12, n.1, p.14-22, 2013

Oliveira, M.F.; Brighenti, A.M. Comportamento dos herbicidas no ambiente In: Oliveira Jr., R.S.; Constantin, J.; Inoue, M.H. (Eds.) Biologia e Manejo de Plantas Daninhas. Curitiba-PR: Omnipax, 2011. Cap. 11, p.263-304.

Osipe, J.B.; Oliveira Jr., R.S.; Constantin, J.; Biffe, D.F.; Rios, F.A.; Franchini, L.H.M. et al. Seletividade de aplicações combinadas de herbicidas em pré e pós-emergência para a soja tolerante ao glyphosate. Bioscience Journal, v.30, n.3, p.623-631, 2014.

Rodrigues, B.N.; Almeida, F.S. (Ed.6). Guia de herbicidas. Londrina: Graf marke, 2011. 697p.

Takano, H.K.; Constantin, J.; Braz, G.B.P.; Lima, M.S.; Padovese Filho, J.C.; Gonçalves, V.D.B. et al. Dry season and soil texture affect the chemical control of Senna obtusifolia in sugarcane. Revista Brasileira de Herbicidas, v.14, n.3, p.181-193, 2015.

Tan, S.; Evans, R.; Singh, B. Herbicidal inhibitors of amino acid biosynthesis and herbicide-tolerant crops. Amino Acids, v.30, n.3, p.195- 204, 2006.

Timossi, P.C.; Durigan, J.C. Doses reduzidas de fluazifop-p-butil + fomesafen no controle de plantas daninhas na cultura da soja. Planta Daninha, v.20, n.3, p.439-447, 2002.

Timossi, P.C.; Durigan, J.C. Manejo de convolvuláceas em dois cultivares de soja semeada diretamente sob palha residual de cana crua. Planta Daninha, v.24, n.1, p.91-98, 2006.

Velini, E.D.; Frederico, L.A.M.; Morelli, J.L.; Marubauyashi, O.M. Avaliação dos efeitos do herbicida clomazone, aplicado em pósemergência inicial, sobre $\mathrm{o}$ crescimento $\mathrm{e}$ produtividade de soqueira de cana de açúcar (Saccharum officinarum cv. SP 71-1406). Stab, v.12, n.2, p.30-36, 1993. 